\title{
Cuidados de Enfermería en el siglo XXI. Una mirada hacia el arte de cuidar
}

\section{Nursing care in the 21st century. A look into the art of caring \\ Cuidados de enfermagem no século XXI. Um olhar sobre a arte de cuidar}

\author{
Amparo Nogales Espert
}

Facultad de Ciencias de la Salud. Universidad Juan Carlos I Madrid.

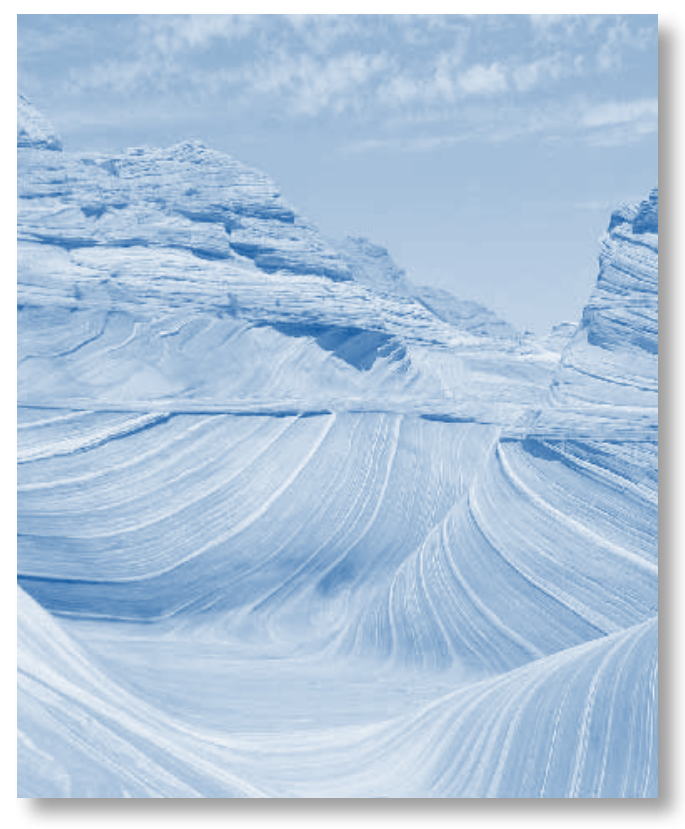

ABSTRACT

This article is the complete version of the paper with which I participated in the roundtable dedicated to the history and phenomenology, on the occasion of the celebration of the XII National Congress, VII International History of Nursing and the VII National Conference on Culture of Care, which took place at the University of Alicante, on 24 November 2011. La paper is divided into two parts, the first part collects and briefly discussed some points, which will undoubtedly help to stay afloat in society current complex and unsettling. The second part is an attempt to approach the deep space of the subtlety and beauty, pointing to the nursing care as a means to achieve a high degree of humanism in the profession.

Key words: History of Nursing, art of care, human dignity.

\section{RESUMO}

Este artigo é a versão completa do papel com o qual eu participei na mesa-redonda dedicada à história e à fenomenologia, por ocasião da celebração do XII Congresso Nacional, História VII Internacional de Enfermagem e da VII Conferência Nacional de Cultura da Care, que teve lugar na Universidade de Alicante, em 24 de novembro de papel 2011.La é dividido em duas partes, a primeira parte coleta e brevemente discutidos alguns pontos, o que certamente contribuirá para manter à tona na sociedade atual complexa e inquietante. A segunda parte é uma tentativa de abordagem do espaço profundo da sutileza e beleza, apontando para o cuidado de enfermagem como um meio para atingir um alto grau de humanismo na profissão.

Palavras-chave: História da Enfermagem, a arte do cuidado, dignidade da pessoa humana. 


\section{RESUMEN}

El presente articulo es la versión completa de la ponencia con la cual participé en la mesa redonda dedicada a la historia y la fenomenología, con motivo de la celebración del XII Congreso nacional, VII Internacional de Historia de la Enfermería y las VII Jornadas Nacionales de Cultura de los Cuidados, que tuvo lugar en la Universidad de Alicante, el pasado 24 noviembre de 2011.La ponencia se divide en dos partes, la primera parte recoge $\mathrm{y}$ analizan brevemente algunos puntos, que sin duda, ayudan a mantenernos a flote en la sociedad actual, compleja y desestabilizadora. La Segunda parte es un intento por acercarnos al espacio profundo de la sutileza y la belleza, apuntando a los cuidados de enfermería, como medio para alcanzar un alto grado de humanismo en la profesión.

Palabras clave: Historia de Enfermería, arte de cuidar, dignidad humana.

Los cuidados de enfermería han mantenido a lo largo de la historia de la humanidad una base y una razón de ser: calmar el dolor, proporcionar confort y bienestar y ayudar en general al enfermo necesitado. Esta ayuda al enfermo ha ido diferenciándose en el transcurso del tiempo y ampliando las formas y posibilidades de ayudar conforme la ciencia y la tecnología médicas han crecido, ampliando las posibilidades de actuar contra la enfermedad, hasta unos límites que hace unos años no nos hubiéramos atrevido a sospechar.

En consecuencia, las posibilidades de curación, recuperación o, en todo caso de mejora de una enfermedad, han crecido de forma exponencial a finales del siglo XX y los albores de siglo XXI en que ahora nos encontramos y por tanto, la esperanza de la humanidad $y$ del hombre de hoy en que la medicina y sus representantes, en nuestro caso la enfermería, tienen conocimientos, es decir, poder, para ayudarles a salir de su estado de enfermedad, ha alcanzado las cotas más altas, nunca hasta ahora logradas en la historia de los cuidados a la persona humana.

En esta intervención, dentro del tiempo que se nos ha asignado, quisiéramos dirigir una mirada hacia el cuidado de enfermería como arte, con el propósito de abrir, en la medida de nuestras posibilidades, un camino quizás estrecho pero, en todo caso, una búsqueda de sentido del arte y la belleza que pudieran constituir una ayuda más a la enfermería para mejorar las expectativas del enfermo actual de recibir más amplios cuidados.

Partiré para este propósito de un convencimiento anterior, el de que, como enfermeras, debemos potenciar nuestra vida interior, especialmente el mundo de la sensibilidad, abierto a recoger sensaciones, impresiones, sentimientos, que nos conforman como personas cada vez más sensibles, para que todo ello pudiera abrirnos a una forma de cuidar especialmente matizada por esta sensibilidad, que abre en nosotros nuevas posibilidades de tomar iniciativas, nuevas formas de estar activas ante el enfermo. Goethe dice así: "Todo objeto nuevo, si lo observamos atentamente, (si somos sensibles a su significado) abre un nuevo órgano en nosotros" (Safranski, 2011:14).

Pretendemos, por tanto, realizar una breve valoración de ciertos aspectos personales, apuntando hacia la búsqueda del encuentro con uno mismo, a fin de ir penetrando en el propósito de llegar a convertirnos en conocedores del espíritu, manteniendo así mismo una observación tranquila y minuciosa frente al mundo exterior, para llegar a ser receptores y motivadores de impulsos. No olvidemos que la enfermera se encuentra ante una persona 
que debe superar a la enfermedad y con frecuencia precisa ser apoyada más allá de lo meramente físico.

Vamos a dividir esta intervención en dos partes. En la primera planteamos unos puntos de referencia sobre cuestiones esenciales del ser humano que nos ayuden a resituarnos en esta sociedad inestable y utilitarista. En la segunda parte intentaremos el acercamiento a una línea en el horizonte de la vida humana, una suerte de skyline o línea en el cielo, aquél espacio profundo de la sutileza y la belleza, para apuntar desde allí a los cuidados de enfermería. Creemos que acercándonos a esta línea en el cielo de lo personal podemos llegar a una actitud estética del espíritu y ver cómo la enfermería puede encontrar otras posibilidades de alcanzar un importante grado de humanismo, ampliando así su espacio en los cuidados.

\section{PRIMERA PARTE:}

En ella recogemos varios puntos de referencia para mantenernos a flote en esta sociedad compleja y desestabilizadora. Estos puntos escogidos, de los cuales realizamos un breve análisis son: 1 dignidad humana, 2 amor como eje de actuación, 3 búsqueda de la verdad y 4 el hombre como ser histórico e incompleto.

\section{Dignidad Humana.}

En reconocimiento de la especial singularidad humana se ha concedido a la persona el calificativo de dignidad. Esta valoración cualitativa, hoy frecuente en nuestro lenguaje, procede de épocas antiguas. Petrarca habló de la dignidad humana, pero especialmente en los albores del Renacimiento, Giovanni Pico de la Mirándola se referirá ampliamente a la dignidad como cualidad del hombre en su libro "Oratio de hominis dignitate"( Pico de la Mirandola, 2004), publicado póstumamente en
1496 y más tarde aparecido como "Discurso sobre la dignidad del hombre".

Afirma Pico de la Mirándola que el hombre es un ser afortunado y merecedor de admiración al poseer unas cualidades, las cuales, por sí mismas, le otorgan este calificativo de dignidad. Son las siguientes:

a. Capacidad de observar, contemplar y apreciar la belleza, como una cualidad excelente, depositada en el espíritu del hombre.

b. Poseer libertad para modelarse a sí mismo, como facultad de elegir entre opciones opuestas, para llegar a una superación de sí mismo, o bien permanecer sin esfuerzo de modificación personal.

c. Poseer una naturaleza dispuesta a adaptarse a nuevas circunstancias y experiencias, a crecer, madurar y dar frutos propios.

d. La persona humana es un ser contemplativo, preparado para recogerse en su interior $y$ ser analítico y reflexivo.

e. El hombre tiene capacidad para llegar a ser todo aquello que se proponga. Puede no contentarse con la mediocridad y aspirar a la excelencia.

f. El hombre es un ser amador, capaz de interesarse y sentir afecto y atracción hacia los demás.

g. Puede desarrollar el hombre su inteligencia mediante razonamiento, buen juicio $y$ vida activa.

Estas cualidades de apreciar lo bello, ser libre y elegir, adaptarse y crecer, contemplar y recogerse en sí mismo, llegar a ser cuanto se proponga, practicar una actitud de amor a los hombres y desarrollar su inteligencia, todas ellas conceden en su conjunto el valor de dignidad a la persona humana, colaborando de este modo a lograr la plenitud de la vida. 


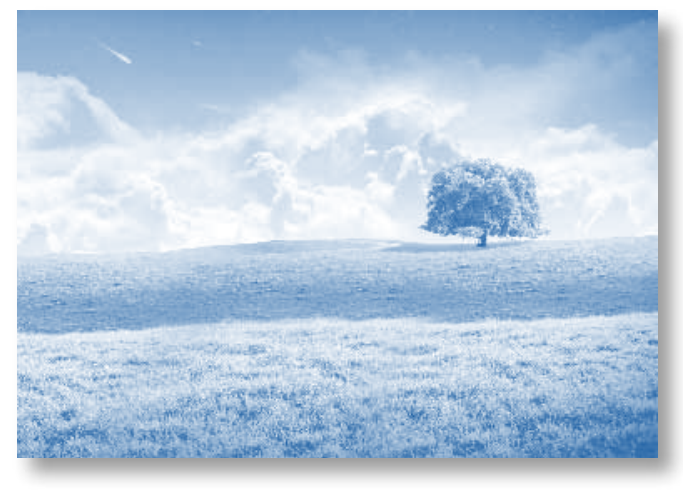

Cuando hablamos hoy de dignidad, deberíamos tener presentes estas potencialidades reunidas en la persona al cuidado de la enfermera, una persona que, en su situación biográfica de enfermedad, mantiene sus cualidades, aspiraciones y esperanzas, como la más elevada forma de realización humana.

\section{Amor como eje de actuación.}

Para alcanzar una vida plena de satisfacción y felicidad, es un factor clave para Eric Fromm, ser capaz de amar. Para este filósofo, uno de los que más se han interesado por el amor humano, éste, el amor, constituye una experiencia personal basada en un interés real por las personas y en una actitud positiva $y$ afectiva hacia ellas. Podemos hablar del amor como una forma de estar ante la vida, expresado, por ejemplo, en el modo de comportarse la enfermera ante los pacientes y en su trabajo.

Se ama con la experiencia, desarrollando una actitud de disposición y unos requisitos tan necesarios para amar como para desarrollar cualquier otro arte, requisitos como disciplina, concentración, paciencia, preocupación, dedicación y buenas condiciones físicas (Fromm, 1994):

\section{Disciplina:}

Resulta imprescindible para practicar cualquier arte, entendiendo amar como un arte.
No hay actividad que pueda considerarse arte si solo se desarrolla esporádicamente. Hace falta, por tanto, una seria disciplina para practicar una actitud de interés y dedicación a los demás, continuamente y sin paréntesis.

\section{Concentración:}

Mantener una actitud consciente en cada actuación, supone saber bien qué hacemos en todo momento. Es una condición importante para practicar un arte, actuar concentradamente con una actitud afectiva hacia la persona cuidada; ello produce resultados estimulantes y beneficiosos para la actividad de cuidar. Actuar concentrado, ayuda así mismo a ser sensibles con uno mismo y a extender esa sensibilidad hacia los demás.

\section{Paciencia:}

Adquirir experiencia en una actividad, en el arte de amar, significa repetir pacientemente esta actitud y mantenerse atento en toda actuación. Es difícil obtener buenos resultados en breve tiempo. Mantener un comportamiento afectivo pacientemente conduce a que fluyan de nosotros disponibilidad, actos de acogida y receptividad hacia los demás.

\section{Preocupación:}

Para practicar un arte, el arte de amar, es importante sentirse interesado en llegar a dominarlo. Esta preocupación se traduce en trabajar a conciencia y en estar pendiente de los objetivos trazados y de los resultados, poniendo empeño en evitar trivializar las pequeñas vivencias experimentadas por la persona cuidada.

\section{Dedicación:}

Es decir, emplearse a fondo en el propósito de aprender a amar de forma satisfactoria, has- 
ta convertirnos en expertos en el arte de amar, en artistas de este arte. Dedicar tiempo a este propósito significa tenerlo en cuenta cada hora de nuestra jornada y cada día, en el trabajo y fuera de él.

\section{Buenas condiciones físicas:}

No es un matiz banal la recomendación de mantener buenas condiciones físicas entre los requisitos para la práctica de amar. Recuperación y descanso adecuados son necesarios para cumplir las exigencias de los cuidados de enfermería, para lo cual se precisa no sentirse cansado, falto de tono activo, en estos casos, falto de motivación para una conducta afectiva.

El amor como experiencia personal consistente en un interés verdadero por las personas $y$ en una actitud positiva y afectiva hacia ellas, hace posible entender el amor de la enfermera hacia la persona enferma, y ofrece la posibilidad de ponerlo en práctica generalizadamente, teniendo en cuenta los requisitos comentados.

No solo amor a las personas, se habla también de amor a los proyectos, a la vida, a las ideas; es necesaria para una existencia plena una motivación hacia el trabajo, las acciones, hacia aquello que se emprende a diario. Goethe lo expresó de este modo: "Si no se habla con una participación amorosa, con cierto entusiasmo parcial, no queda nada digno de hablarse. El agrado, la alegría, la participación en las cosas es lo único real y lo único que trae de nuevo realidad, todo lo demás es fútil y frustrante", (Safranski, 2011).

Viendo el amor desde otras perspectiva, podemos decir que el amor da felicidad, que amando se es feliz, que amando se da, y que nos sentimos en verdad tanto más felices, cuanto más damos de lo nuestro y de nosotros mismos. De tal manera que aquél que no da algo de sí, finalmente pierde. Así lo dice Séneca en una obra sobre la felicidad, "De vita beata": "Nunca hago mejores inversiones que cuando doy. Pues qué, me dirás, ¿das para recibir?. No, doy para no perder”, (Marías,2002:31).

\section{Búsqueda de la verdad.}

Vivir la enfermería como una gran aventura significa darnos cuenta de los importantes descubrimientos que nos permite realizar, de las decisiones que tomamos en su ejercicio $y$ de las que nos esperan, algunas determinantes para nuestra existencia. Vivir la enfermería como una aventura significa que en ella depositamos nuestros proyectos, nuestras inquietudes y esperanzas. Nos ofrece la posibilidad de encontrar la belleza y la grandeza de la vida y, puesto que también nos muestra la proximidad de la muerte y su condición final de inevitable para el hombre, la enfermería nos incita, mientras transcurre nuestro camino entre la vida $y$ la muerte, a caminar en busca de la verdad.

La enfermería, en su trato con la enfermedad y la muerte, nos plantea una actividad apasionante, la de buscar respuestas a las inquietudes fundamentales y últimas del ser humano, las de encontrar la ilusión de transmitir la esperanza a los corazones atenazados por la enfermedad.

La enfermería nos lanza a encontrar la luz para comprender mejor nuestro quehacer, nos empuja a encontrar los fundamentos sólidos del cuidado, a buscar más allá de la capacidad técnica, la cual, si se reduce a sí misma solo deja una visión sesgada de la enfermería.

La enfermería favorece en nosotros la disposición para buscar la verdad del ser humano y de la vida propia, nos coloca tan cerca de la humanidad que, aún en estos tiempos en los cuales se nos presenta al hombre como simple consumidor, podemos también adivinar el 
espíritu humano, seguir indagando sobre las cuestiones esenciales del hombre, al tiempo que convivimos con el final y el principio de la vida y el dolor de la existencia humana. ¿Es posible experimentar el impulso hacia delante de la enfermería?.

Quizá lo experimenten aquellas enfermeras abiertas a las vibraciones de su ejercicio en los diferentes momentos de su actividad profesional. Quizá podamos experimentar el impulso del cuidado sobre el cuidador, siendo enfermeras convencidas de la capacidad de avanzar en el camino hacia la verdad, existente en la persona humana.

La aspiración a buscar la verdad nos acompaña a lo largo de la historia del pensamiento, tal como lo tuvo previsto Platón: "Busca la verdad mientras eres joven, pues si no lo haces, después se te escapará de entre las manos" (Ratzinger, 2011:62).

El camino hacia la verdad total necesita siempre una actitud humilde. Nunca llegaremos a la verdad completa, Somos inconclusos caminantes en un proceso incompleto de formación y transformación.

Ratzinger piensa: "La verdad misma siempre va a estar más allá de nuestro alcance. Podemos buscarla y acercarnos a ella, pero no podemos poseerla del todo: más bien es ella la que nos posee a nosotros y la que nos motiva. En el ejercicio intelectual y docente, la humildad es así mismo una actitud indispensable, que protege de la vanidad que encierra el acceso a la verdad" (Ratzinger, 2011:63).

\section{El hombre como ser histórico}

Somos seres históricos precisamente por tener una vida inconclusa, porque la vida humana, mientras es vida, está recorriendo un camino a lo largo del cual, el hombre constantemente cambia y se modifica, experimenta, aprende y olvida, siente de una determinada forma, tiene nuevas preferencias y abandona otras.

El hombre tiene conciencia de ser y de estar siendo y, además, tiene conciencia de poder ser, lo cual significa que en el ahora de la persona se encuentran las innumerables posibilidades de ser en el futuro.

"El hombre es animal histórico, viviente, capaz de progresar y de regresar, cosa que en modo alguno puede decirse de cualquier especie animal... La conducta del hombre en cambio, y tanto en su vida individual como en su vida específica, va cambiando constantemente a lo largo de su edad, es "idem sed aliter", lo mismo pero de otro modo, y esto da carácter histórico, tanto a la vida del individuo humano, como a la del grupo social al que pertenece" (Ratzinger, 2011:63).

Desde esta visión del hombre como ser histórico y por tanto inacabado, o en devenir, en sucesión y transformación, tomamos la propuesta de Edith Stein, que da título a una de sus obras filosóficas: “Acto y potencia”, (Ratzinger, 2011:63). Para enlazar con el hecho histórico de la vida humana, y decir que, tal vez el carácter inconcluso de la vida del hombre, pueda hacer que veamos en el acto humano, en la actuación puntual en un cuidado concreto, la potencia de los actos futuros, de lo que puede llegar a realizar el cuidador y todavía no se ha concretado en una realidad. Probablemente el acto humano (de la enfermera que cuida), encierra la potencia de los actos realizables en el futuro.

Como ser histórico, la persona enfermera puede pretender caminar progresivamente, aunque sea de manera fragmentaria, hacia la asimilación de los conocimientos necesarios para proporcionar cuidados más satisfacto- 
rios para el paciente y para sí misma, desde los cuatro puntos de referencia aquí presentados: conservar la dignidad humana; amar como eje de actuación, búsqueda de la verdad y considerar al hombre como ser histórico.

En relación con los dos últimos puntos, búsqueda de la verdad y contemplar al hombre como ser histórico, ponemos sobre el papel las palabras de Edith Stein: "Ningún sistema de pensamiento humano alcanzará jamás un punto de perfección tal que pueda satisfacernos... también puede ser el camino que conduzca a un contacto vivo con los antiguos pensadores y a la comprensión de que, a pesar del tiempo y de las barreras constituidas por las naciones $y$ las escuelas, todos los que buscan realmente la verdad tienen algo en común" (Stein,2004:14).

Respecto a los dos primeros puntos comentados anteriormente, dignidad humana y amar como eje de actuación, vamos a fijarnos, para terminar esta primera parte, en la visión de Ortega y Gasset en su consideración de la vida humana como realidad radical, como punto de origen de todas las posibles actividades de la vida. En esa realidad radical, se encuentran todas las formas de experiencia de lo real. Y esas formas de experiencia de lo real, que seguidamente presentamos, incluyen actividades por las cuales el hombre tiene reconocida su dignidad: inteligencia, imaginación, apertura al futuro, ensimismamiento y soledad, capacidad de juzgarse, libertad y responsabilidad. El hombre es acreedor de dignidad, por su capacidad para actuar abierto hacia el amor como una necesidad humana preferente, a través de la convivencia social.

Veamos las actividades de la vida humana concebidas por Ortega y Gasset como realidad radical:

1. "Ejercitar mi inteligencia como razón vital, y puesto que existo en la historia, como ra- zón histórica. Solo considerada como función de la vida puede entenderse realmente lo que es la razón. Apoyada en creencias y experiencias, nuestra razón produce ideas, y tanto mis creencias como mis ideas están radicadas en mi vida y para mi vida”.

2. "Proyectarme imaginativamente hacia el futuro desde mi pasado actualizado en $\mathrm{mi}$ presente. El recuerdo es la carrerilla que nos tomamos para dar un enérgico salto hacia el futuro. La futurición es nota esencial de la existencia humana; el hombre es un ser futurizo, dirá Julián Marías".

3. "Crearme a mí mismo, realizando bien o mal el futuro imaginado y proyectado. Vivo hacia el futuro, sintiéndome a mí mismo, o juzgándome a mí mismo, imaginándome a mí mismo, creándome a mí mismo”.

4. "Convivir humanamente con los demás, tanto de un modo social, esto es, con los hombres para mí presentes, como de un modo histórico, con los hombres para mí pretéritos. La razón vital se hace así razón histórica, y cada vida se convierte en un punto de vista dentro del todo de la humanidad. Existir es coexistir".

5. "Ensimismarme, recluirme en lo más íntimo de mi mismo. Por tanto vivir experimentando que el elemento de que estoy hecho, que el hilo de que estoy tejido, es la soledad".

6. "Juzgarme moralmente a mí mismo por el modo como he realizado mi libertad. Vivir según la condición de realidad radical que para el hombre es la vida, lleva esencialmente consigo la responsabilidad", (Lain, 1998:118).

\section{SEGUNDA PARTE}

Intentamos acercarnos a una línea en el horizonte de la vida enfermera, el espacio profundo de la sutileza y la belleza apuntando a los cuidados de enfermería. Creemos que, acercándonos a esa línea, en la dimensión 
transcendente de la vida humana, a una actitud estética del espíritu, la enfermería puede llegar por otras vías a alcanzar un respetable grado de humanismo, ampliando así su espacio en los cuidados.

El arte se ha representado referido a la enfermería a lo largo de la historia; en España no han faltado obras publicadas de enfermería en las que aparece el arte como elemento propio de enfermería. Recordemos la "Instrucción de Novicios de la Orden de la Hospitalidad. Tomo 2, Arte de Enfermería”. P. José Bueno y González O. H. Madrid, 1833, (Ventosa, 2011). La enfermería ha sido transmitida como ciencia y arte en gran parte de las Escuelas de Enfermería españolas del siglo $\mathrm{XX}$, aunque después la consideración de arte haya sido abandonada al olvido, desde el punto de vista formativo.

Hemos dividido esta segunda parte en los siguientes apartados:

1. La belleza en el ámbito de enfermería

2. Pintura y arte de enfermería

3. Literatura y arte de enfermería

4. Arte actual y arte de enfermería

5. Práctica y arte de enfermería

\section{La belleza en el ámbito de enfermería}

Umberto Eco en su "Historia de la belleza" utiliza el adjetivo de bello para calificar una cosa que nos gusta. Además no solo nos parece bello aquello que nos gusta, sino que quisiéramos poseerlo. Resulta bella una cosa que estimula nuestro deseo. Otras veces se califica de bella una acción, como la del que cuida a un leproso. En definitiva, dice Eco, "hablamos de belleza cuando disfrutamos de algo por lo que es en sí mismo, independientemente del hecho de que lo poseamos. Es bello aquello que, si fuera nuestro, nos haría felices, pero que sigue siendo bello, aunque pertenezca a otra persona”, (Eco, 2010:8).
La relación entre belleza y arte es la siguiente: mientras la belleza puede ser una cualidad poseída por ciertos elementos de la naturaleza (un hermoso árbol, un bello claro de luna), la función del arte consiste en hacer bien las cosas que hace, de manera que resulten útiles a la finalidad que tienen asignada, de forma que hacen arte el escultor, el barquero o el barbero que fabrican una bella cosa, una escultura, una barca o un corte de pelo. Han sido artistas por tanto, todos ellos, al igual que los poetas y escritores que han explicado qué era para ellos lo bello y han producido obras bellas.

El ideal de belleza también es diferente en uno u otro momento de la historia, según las culturas y las épocas. De este modo no puede hablarse de belleza como de algo inmutable, puesto que ha ido adoptando distintos prototipos en cada momento histórico. Diferentes pintores han sostenido distintos modelos de belleza según cada país y época histórica, incluso puede decirse que varios modelos de belleza coexisten en una misma época.

La bella acción de cuidar a un enfermo, no está sujeta a estos cambios, contrariamente se mantiene inalterable, debido a que la sensación de ser cuidado con arte la experimenta el enfermo, y responde invariablemente a un cuidado afectivo, junto a la satisfacción de necesidades básicas.

Veamos como ejemplo la referencia a los cuidados prestados por San Juan de Dios a los enfermos en el siglo XVI, dejando al lector la libertad de opinar si a esto podría llamarse arte y bello cuidado; si los enfermos al ser tratados de esta manera se sentirían cuidados con arte y si, finalmente, un enfermo del siglo XXI al verse atendido de semejante forma, no podrá sentir que es cuidado con arte: “Todo el día se ocupaba en diversas obras de caridad, y a la noche, nunca se recogía sin primero visitar a 
todos los enfermos, uno a uno, y preguntadles cómo les había ido, y cómo estaban, y qué habían menester, y con muy amorosas palabras consoladlos en lo espiritual y temporal", (Castro,2011:25).

\section{Pintura y arte de enfermería}

Sin duda el arte de la pintura deja en la enfermera resonancias influyentes para el arte de cuidar. Recordemos, aunque sea muy brevemente, algunos aspectos de las obras de Leonardo de Vinci, (Vezzoli, 2011). En el taller de Verrochio en Florencia, donde ya se vive un refinado humanismo, se despiertan en Leonardo sus extraordinarias dotes de observador, dibujante y pintor. Más tarde en su "Tratado de la pintura”, hablará con entusiasmo del estímulo provocado en su imaginación por las manchas en la pared, "porque en las cosas indefinidas el espíritu se abre a nuevas invenciones" (Vezzoli, 2011:28). En sus obras Leonardo comenzará a experimentar una nueva sensibilidad ante las sugerencias expresadas por la luz, a la que logra hacer vibrar en distintos juegos de densidad e intensidad.

Obra fundamental en la formación de Leonardo es "La Anunciación”, realizada en el taller de Verrochio, junto con otros alumnos, considerada después obra maestra del Quatrocento, imprescindible para admirar el proceso artístico vivido en los talleres de la época, desde el proyecto iconográfico, el dibujo preliminar y los posteriores toques pictóricos, con las siguientes intervenciones especializadas. La intervención directa de la mano de Leonardo se produjo sobre la cabeza del ángel y de la Virgen, las ropas y el paisaje, según opinan los expertos.

El conjunto del cuadro resulta de una belleza cautivante, la actitud reverente del ángel, en un rostro afable y al mismo tiempo consciente

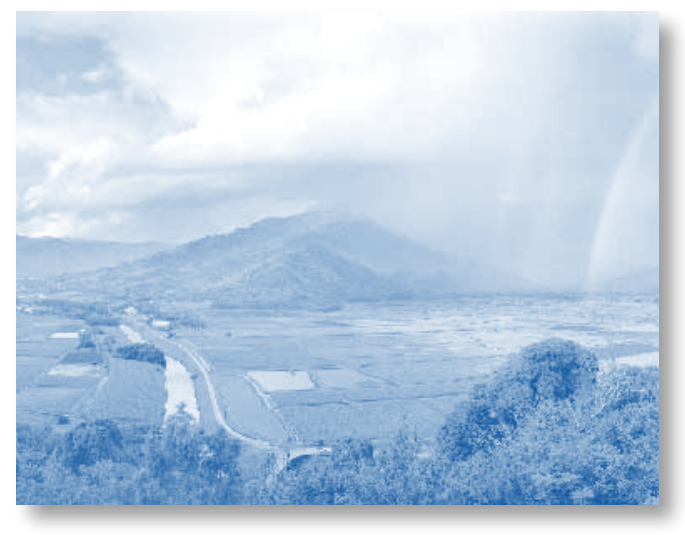

de la magnitud de su revelación, junto a una actitud de reconocimiento hacia la otra persona, presenta una figura enfundada en ropajes de gran elegancia y representatividad. Al otro lado, la Virgen, mostrada en un joven rostro expresando a un mismo tiempo serenidad y expectación, con el brazo derecho en reposo y el izquierdo levantado en leve actitud de sorpresa, revestida su persona de vestimenta llena de elegancia y sencillez.

Solamente las figuras, sin ocuparnos del resto del cuadro, encierran una muestra palpable de haber captado el significado del acto y potencia (ya mencionado más arriba), plasmado en una instantánea. Se trata de un instante singular en el cual un enviado de Dios viene a comunicar un hecho trascendental. La otra figura, la de la virgen María, deja traslucir a través de su expresión corporal, su vestimenta, gesto y sobre todo su rostro, serenidad y expectación a un mismo tiempo. Este es el acto, el hecho plasmado en el cuadro. Pero así mismo, el propio acto que se muestra, contiene la potencia, no de lo que está siendo, sino de la consecuencia, de lo que puede ser y aquello que realmente será después. En el acto inmóvil aparece la fuerza de aquello que ocurrirá más tarde. El conjunto del cuadro, con las vestimentas, posturas y rostros de las dos figuras sobre el telón de fondo en el cual son presen- 
tadas, transmite la sensación de estar ante un instante grandioso.

El otro ejemplo que hemos tomado de Leonardo es la Monna Lisa. En su conjunto toda la representación consiste en una figura de mujer, sobriamente vestida con ropajes en tonalidades oscuras, sobre un fondo de naturaleza también oscuro, para resaltar la figura femenina y en especial el rostro. La posición corporal de la joven retratada es reposada, con ambas extremidades apoyadas en los brazos de una silla en la cual aparece sentada; la mano derecha sobre la izquierda y aquélla con los dedos separados en actitud de relajación.

Todo el cuadro atrae la atención del observador sobre el rostro de Monna Lisa, y ésta parece lanzar interrogantes a todo aquél que la contempla, de tal modo que el observador queda atrapado por la fuerza de un rostro $y$ una sonrisa enigmáticos.

Después de la primera impresión el observador del cuadro cae en la cuenta de que los ojos de Monna Lisa no le miran fijamente a él, sino que están mirando de reojo hacia su izquierda, a la vez que sonríe levemente. Lo que realmente parece querer mostrar el pintor es la figura, presente y estática en el acto de estar ahí $y$, en ella, la potencia de aquello que comienza a suceder en su persona. ¿Qué es lo que está contemplando la joven?; ¿hacia dónde dirige su pensamiento?; ¿qué ocurrirá en Monna Lisa en el instante después de pasar por el pintor?.

El hecho cautivador del cuadro está en la perfección de la pintura y en el poder de atracción de un rostro, que comienza interpelando al observador y sonriéndole con sonrisa benevolente, para pasar después a una mirada dirigida a otro lugar más allá del observador, en un ejercicio de introspección reflexiva verdaderamente enigmático, como guardando un secreto que no desea comunicar. Este es el mis- terio conservado en el lienzo desde hace más de cinco siglos.

¿Dónde encontrar el valor del arte de la pintura para el arte de enfermería?. La pintura hace de la persona, y de la persona enfermera, una experta en observación, transmitiendo con la experiencia mayor grado de sutileza para captar detalles de la figura y la relación con el enfermo que, por su profundidad, o por su levedad, pasan sin duda desapercibidos. La enfermera experimentada en observación, puede advertir mensajes gestuales que, en muchos casos pueden no ser recogidos. Y aprende en todo caso, dos cosas importantes: una la disposición con la que hay que acercarse al cuadro y a la persona a su cuidado, para recoger la mayor información posible, y dos, aprende a encontrar la belleza en las obras de arte y la belleza, a veces escondida en la persona a su cuidado, y a disfrutar de ambas. Es de esperar que un cuidado en estas condiciones se convierta realmente en arte.

\section{Literatura y arte de enfermería}

$\mathrm{El}$ arte en todas sus experiencias pertenece a la vida. A través de la literatura el arte se expresa hasta cimas difícilmente superables. Veremos varias muestras del arte, su expresión y manifestación a través de los escritos de dos grandes poetas y escritores de todos los tiempos: Goethe y Schiller, a finales del siglo XVIII.

Para Goethe el arte viene a ser un cobijo contra los hechos negativos ocurridos en la historia. Para Schiller el arte es "un impulso originario de la libertad". Por eso en sus "Cartas de Kallias", quiere presentar una nueva teoría de lo bello diciendo: "la belleza es libertad en aparición”, (Safranski, 2011:90-91). Hay ahí una autodeterminación en el hombre al crear belleza, y en la naturaleza al mostrarse de manera bella. En el mundo estético de Schiller 
entran en juego la belleza, la gracia y la dignidad, cuando relaciona la belleza corporal con el vestido, los ropajes: "La belleza es el conjunto logrado entre el vestido y el cuerpo. En ese conjunto cada elemento logra su mejor forma y hace posible con ello la bella impresión del todo". Este es el pensamiento fundamental sobre la belleza: "la belleza juega con los materiales, las cosas, las materias, las ideas, el lenguaje, de modo que expresa su correspondiente sentido y valor propio, y así éstos permanecen libres y a la vez quedan incluidos en un todo" (Safranski, 2011:92).

En el "Tratado sobre la gracia y la dignidad" de 1793, Schiller define la gracia como "la reconciliación entre el impulso y la libertad, naturaleza y razón". Si se logra esta reconciliación el hombre se convierte en "alma bella", definida de este modo: el alma bella... "con gran facilidad, como si desde ella actuara solo el instinto, practica los deberes más penosos de la humanidad, y el sacrificio más heroico que arranca a las tendencias naturales, se presenta ante nuestros ojos como la acción voluntaria de esa tendencia”. Así pues, "el deber no ha de dominar sobre el querer, sino que el querer ha de ser cultivado por el arte, de tal manera que asuma el deber en su voluntad". "En ocasiones, debo forzarme a algo. En estos casos no se muestra belleza ni gracia, pero sí, en cambio, dignidad", (Safranski, 2011:92).

Mientras para Schiller la belleza se define como "libertad en la aparición", para Goethe en su ensayo de 1794 titulado "En qué medida la idea de que la belleza es perfección unida con la libertad puede aplicarse a las naturalezas orgánicas" afirma sobre la belleza: "No es el movimiento lo primero en ser bello, sino que ya lo es el aspecto de una figura concentrada vigorosamente en sí misma, como la de un león, en el que se echa de ver que le es posible u múltiple uso libre de todos sus movimientos, tan pronto como él quiera, de modo que el supremo sentimiento de belleza, va unido con el de confianza y esperanza”, (Safranski, 2011:108).

Safranski opina": Sin duda la ciencia puede aprenderse, pero, ¿también la gracia?. Es evidente que no, pero en todo caso, la cabeza técnica puede aprender a escuchar mejor las sensaciones, no para dejarse llevar al lado de ellas, sino con el fin de usarlas para los propios fines sin infringirles violencia”, (Safranski,2011:111-112). Sobre el arte Schiller opina: "el arte crece en perfección cuanta más artificiosidad pierde y más se acerca a la coherencia orgánica con la naturaleza; $y$, a la inversa, la naturaleza, con su finalidad sin fin, aparece como una obra de arte”, (Safranski, 2011:162).

Goethe escribirá la "Teoría de los colores”, dando vuelos mucho más lejanos a su idea del arte y de la belleza, situando al amor muy cerca de la belleza y la satisfacción de la vida, con esta frase ya expresada más arriba: "Si no se habla con una participación amorosa, con cierto entusiasmo parcial, no queda nada digno de hablarse. El agrado, la alegría, la participación en las cosas es lo único real y lo único que trae de nuevo realidad, todo lo demás es fútil y frustrante”, (Safranski, 2011:164-165).

La necesidad de apertura hacia uno mismo y ante la vida, las cosas y la naturaleza es el punto de partida para captar la belleza allá donde se encuentre. Veamos la opinión de Goethe, de Schiller y de Safranski en este sentido:

Goethe: "Cerrados frente al propio interior, (los hombres) se pierden en la distracción. Aquí no puede abrirse paso ningún temple poético".

Schiller: "Si falta ese temple, el hombre no experimentará lo simbólico en los objetos. La riqueza de significación del objeto es una 


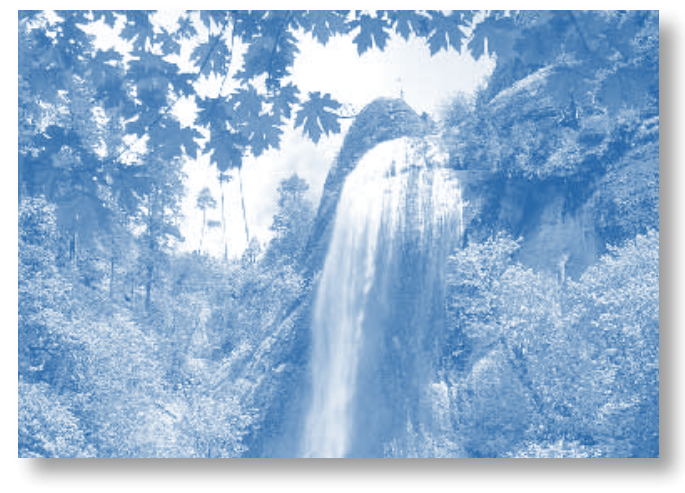

función de la plenitud de significación del sujeto. Si el hombre tiene esa plenitud de significación, cada calle, puente, nave, e incluso un arado, será capaz de comunicarle alguna cosa".

Para Safranski, en ambos pensadores, Goethe y Schiller, "los objetos no revelan su riqueza por sí mismos, sino solamente a través de un sujeto desarrollado; se trata aquí de un fenómeno de resonancia. Hay que abrir el objeto, cosa que solo puede hacer un sujeto que se abre. ¿Cómo lo logra?. No solo por la relación consigo, sino además, por la relación con el mundo. Por tanto, el proceso de apertura es recíproco. Cada uno se experimenta a sí mismo a través del mundo, y experimenta el mundo a través de sí mismo", (Safranski, 2011,195). Finalmente, frente a la captación de la belleza y creación del arte, Schiller opinará que "es la actitud estética del espíritu la que produce todo esto, el temple estético del espíritu", (Safranski, 2011:202).

Para enfermería la belleza es también "libertad en aparición", la aparición de un cuidado con arte en la libertad de practicarlo por parte de la enfermera cuidadora, la cual ha tomado esta autodeterminación. En la estética de Schiller belleza, gracia y dignidad aparecen relacionadas, mostrándonos a las enfermeras, cómo gracia y dignidad van unidas a belleza, pues la belleza se expresa a través de materiales, objetos, palabras y gestos, y hasta en la forma de llevar el vestido, un uniforme puede expresar belleza.

Un alma bella, "practica los deberes más penosos de la humanidad", los cuidados de enfermería más desagradables, hechos bellamente, convierten a la persona enfermera en un alma bella. El deber no ha de dominar sobre el querer; la enfermera trabaja bellamente porque quiere hacerlo así. Lo que se muestra entonces hacia fuera es la dignidad de esta profesional.

Para Goethe la belleza está ya presente en la persona, incluso antes de la acción, en la figura enfermera, podríamos decir, "vigorosamente concentrada en sí misma", pues en ella está presente la posibilidad de movimientos y acciones, y así, "el supremo sentimiento de belleza va unido con el de confianza y esperanza", dice el escritor. Confianza y esperanza es lo que debe desprenderse de la persona de la enfermera.

¿Cómo aprender la gracia desde la técnica?. Escuchando mejor las sensaciones. O sea, aguzando la observación y la sensibilidad. Puede lograrse a través de la afición al arte, en este caso, la literatura.

En una actitud amorosa ante la vida y en la relación con las personas hay, así mismo, belleza para Goethe.

Permanecer abiertos a la vida, y también ante la naturaleza y las cosas son el inicio para captar la belleza allí donde esté, en la figura, las palabras o las acciones de un enfermo, por ejemplo.

La riqueza de significados que pueden tener los objetos, la naturaleza o las personas, no están solo contenidos en ellas mismas, sino sobre todo, en el temple, en la plenitud del sujeto para captar significados, en la enfermera preparada, en nuestro caso. Y si la enfermera está bien dispuesta, la naturaleza, las cosas y 
las personas le comunicarán alguna cosa. De modo que para Goethe y Schiller "los objetos no revelan la riqueza por sí mismos, sino a través de un sujeto desarrollado, pues se trata de un fenómeno de resonancia”. Y así en la enfermera sensibilizada para captar la belleza resuena y se hace patente la belleza que le revelan la naturaleza, las cosas y las personas. "Hay que abrir los objetos (cosas, personas), dicen los autores, y esto solo puede hacerlo un sujeto que se abre”. ¿Cómo se hace?. Mediante un proceso de apertura de uno mismo, y ante la naturaleza, siendo receptivo.

¿Qué nos hace producir arte?. Dice Schiller, la actitud estética del espíritu, el temple estético del espíritu. La disposición, preparación, apertura y voluntad.

\section{Arte actual y arte de enfermería}

En el arte actual, la arquitectura y cualquier arte en general se convierten en asunto de reflexión. Pongamos como ejemplo a la artista Fernanda Fragateiro, Portugal 1962, que muestra en las formas y texturas de sus obras escultóricas, sus motivaciones y respuestas al arte, (Fragateiro, 2011).

Es necesaria una mirada sosegada para recoger las sensaciones de sencillez y delicadeza reveladas en sus esculturas. "La belleza, dice la artista, es un arma poderosa”. La obra de arte solo existe cuando sale afuera, cuando se comunica. El arte de enfermería se genera no cuando se presenta impreso en un papel, sino cuando aparece en el hacer y ser de la enfermera. Es entonces cuando el arte de enfermería sale al espacio y puede ser visto desde el exterior y sentido por el enfermo que lo recibe y por la propia enfermera, desde cuyo ser y hacer se genera.

Para Fragateiro,"hasta el más mínimo detalle tiene un sentido; todo cambio, por pequeño que sea, implica un nuevo rumbo. Y creo, dice, en la magia de los materiales y de la obra de arte" (Fragateiro, 2011:27). Desde este punto de vista, la primera actitud de la enfermera consciente del arte de enfermería, será permanecer alerta para percibir el más mínimo detalle del entorno y del propio enfermo, para recoger hasta el más pequeño cambio, pues ellos apuntan hacia un nuevo rumbo que está ocurriendo en la situación, en el ambiente o en el estado de animo del enfermo y aún de la propia enfermera.

El mundo, para un artista no debe verse desde una posición cerrada, coincidiendo aquí con la importancia de permanecer abiertos propuesta por escritores clásicos. Hace falta una actitud personal, una disposición del profesional. La artista Fragateiro expresa: "Me gusta llegar a un lugar, tirar de él como si de un hilo se tratara y alcanzar otro punto", (Fragateiro, 2011:27). Todo lo contrario es mostrarse indiferente ante el entorno y a cuanto ocurre; la autora propone actuar, tomar la iniciativa como artista, tirar del hilo de la situación, actuar con gestos, palabras, actitudes. El arte de enfermería solo puede ponerlo en movimiento la enfermera.

En la visión más actual del arte, Fragateiro no ve la utopía como algo imposible, "la utopía, expresa, es simplemente querer llegar a un sitio mejor" (Fragateiro, 2011:27). En una aplicación correspondiente, podríamos ver el arte de enfermería, aún en nuestros días, no como una utopía inalcanzable, sino sencillamente, como un camino hacia algo mejor.

Destacar por lo que hemos visto, como realmente llamativo y aplicable al arte de cuidar en 2011, que trabajar en enfermería con sutileza, entendida como poder de penetración, como habilidad para hacer algo primorosamente, significa comprender que esta dis- 
posición sutil, es para el artista un arma que transforma la sociedad (Fragateiro, 2011:27).

\section{Práctica y arte de la enfermería}

El arte de enfermería está presente en nuestra historia. En el libro "Instrucción de Nobicios del Orden de la Hospitalidad" (San Juan de Dios) de 1668, figura una detallada normativa sobre los cuidados puntuales que deben aprender los novicios, de los que veremos algunos ejemplos. Lo interesante es que esta obra se revisa en 1833, y aparece con un nuevo título, "Arte de enfermería", al que ya nos hemos referido. De modo que los ejemplos presentados a continuación, son realmente considerados arte de enfermería desde mediados del siglo XVII hasta bien entrado el siglo XIX:

1. El cuidador "debe de tener un ánimo dilatado y sin límites... ha de considerar que

va a ser sirviente... no menospreciando obrar con esa perfección aún las cosas que son de poco momento".

2. Al hacer la cama del enfermo, "nunca le acostará en cama agena, manifestando

con el cariño del obrar, que la caridad... aparta todo temor de daño que de la obra pueda resultar".

3. "Acabado de hacer las camas, serán los Nobicios los primeros en el limpiar de los vasos y tomar las escobas para barrer".

4. “... Luego les lave los pies y se los bese con toda caridad. Después le desnude, acueste y anime con la esperanza de la salud".

5. “... A los que estuviesen sangrados, se mire tal vez si la venda de la sangría esta

bien atada, que sin duda es grande el peligro que hay en no estando".

6. "Procure el Nobicio llevar la comida al enfermo más necesitado, a quien animará

con amorosas palabras a que coma; y si fuere necesario le ministrará la comida a la boca”.
7. "De la necesidad que hay de que el enfermero sea cuidadoso y prudente en el servicio de los enfermos".

8. “... También se requiere que el que los ha de aplicar (los remedios), los execute con fidelidad, diligencia y prudencia”.

9. "Que sea puntual la execución del que sirve en lo mandado... Asentada esta verdad de cuan necesaria sea la puntualidad del enfermero para que ella sea más perfecta es necesario que el tal enfermero entienda algo del pulso, sepa sangrar, y aún hacer alguna substancia y almendrada y también tener mucha noticia de los remedios que aquí se ponen, y del modo de ejecutarlos y de otros" (Victoria, 1668: 117129 y $324-327)$.

En estos textos encontramos plasmado el arte de enfermería. Si quisiéramos mirar hacia el arte de cuidar del siglo XXI, tendríamos que contemplar cómo se materializa el arte de enfermería en nuestros días, y podríamos decir que el arte es hoy un despliegue interior de la enfermera, en cuanto persona, dispuesta a ayudar en todo a la persona necesitada en la aplicación de los cuidados.

Tendríamos que decir, en segundo lugar, cómo se contempla el arte de los cuidados, para ver que se encuentra en la visión, aplicación y recepción de estos, es decir, qué observa el que ve los cuidados, el que los ve y los aplica, y el que ve y recibe dichos cuidados.

En tercer lugar, precisando un poco más formularíamos la pregunta: ¿dónde está el arte de los cuidados?. Para responder que el arte de cuidar se encuentra realmente en la propia persona enfermera, su imagen y su expresión; en aquello que hace en la aplicación de cuidados y técnicas, y en el sentimiento que todo ello provoca en quien lo observa, lo ejecuta $y$ en aquél que lo recibe. 


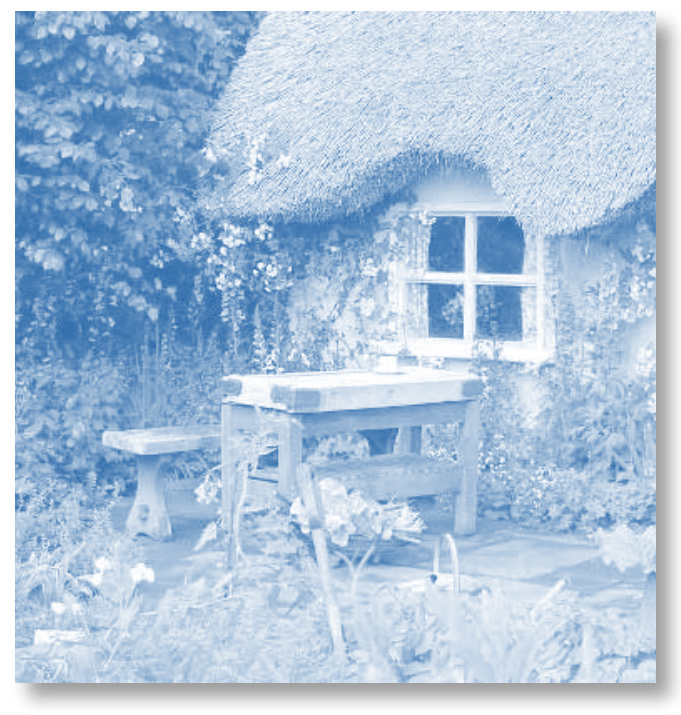

\section{CONCLUSIONES}

Para terminar con una última mirada hacia el arte de cuidar en el siglo XXI basándonos en los aspectos comentados en esta intervención, vamos a manifestar que nuestro reto actual consiste en una apertura radical hacia lo otro distinto a mí; apertura hacia las personas, momentos y ambientes, más allá de uno mismo. Dicha apertura solo puede pasar a través de una disposición personal y un aprendizaje, incluyendo siempre en el centro de nuestra vida, a las otras personas.

Como ya ha sido expresado, "el centro de la vida humana, no es el yo, sino el tú, lo cual significa que el centro de gravedad de mi acción y de mi pensamiento, están fuera de mí mismo" (Torralba, 1998: 323).

No quisiera terminar esta intervención sin dejar expresado mi agradecimiento hacia mi profesión de enfermería y de historia, de las que he recibido mucho. Y manifestar a ustedes mi profundo reconocimiento por prestar atención a unas reflexiones que no se si pueden ser de alguna utilidad, pero solo con que hayan merecido su atención en algún pequeño aspecto, aunque sea mínimamente, me daría de sobra por satisfecha.

\section{BIBLIOGRAFÍA}

- De Castro, F. (1585) Historia de la vida y sanctas obras de Joan de Dios y de la institución de su Orden. Granada f 44 v. 45. En: Ventosa E, F. (2011) Pensamiento de San Juan de Dios y la Orden Hospitalaria y su relación con la enfermería: Conceptos y valores. Tesis Doctoral. Madrid.

- Eco, U. (2010) Historia de la belleza. De bolsillo. Barcelona.

- Fragateiro, Fernanda. La sutileza es un arma poderosa. Diario ABC. Cultural, Madrid, 24 Septiembre, 2011, pp. 27-27.

- Fromm, E. (1994) El arte de amar. Paidos. Barcelona.

- Lain E, P. (1996) Idea del hombre. Galaxia Guttemberg. Circulo de Lectores. Barcelona.

- Lain E, P. (1998) Alma, cuerpo, persona. Galaxia. Guttemberg. Circulo de Lectores. Barcelona.

- Marías, J. (2002) Sobre la felicidad. Séneca. Alianza Editorial. Madrid.

- Pico de la Mirandola, G.(2004) Discurs sobre la dignitat de l'home. P.U.V. Valencia.

- Ratzinger, J. (2011) Discursos e intervenciones. Jornada Mundial de la Juventud. San Pablo. Madrid.

- Safranski, R. (2011) Goethe y Schiller. Historia de una amistad. Tusquets. Barcelona.

- Stein, E. (2004) Ser finito y ser eterno. Fondo de Cultura Económica. México.

- Torralba, F. (1998) Antropología del cuidar. Fundación Mafre Medicina. Madrid.

- Ventosa E, F. (2011) Pensamiento de San Juan de Dios y la Orden Hospitalaria y su relación con la enfermería: Conceptos y valores. Tesis Doctoral. Madrid.

- Vezzoli, A. (2011) Leonardo Da Vinci. Arte y ciencia del Universo. Blume. Barcelona.

- Victoria, O. H. A. (1668) Instrucción de Nobicios del Orden de la Hospitalidad. En: Ventosa E, F. (2011) Pensamiento de San Juan de Dios y la Orden Hospitalaria y su relación con la enfermería: Conceptos y valores. Tesis Doctoral. Madrid, pp. 197-200. 